\title{
Erratum to: Lifespan development of the bilateral deficit in a simple reaction time task
}

\author{
Solveig Vieluf ${ }^{1,2} \cdot$ Gisa Aschersleben $^{3} \cdot$ Stefan Panzer $^{1}{ }^{1}$
}

Published online: 15 February 2017

C) Springer-Verlag Berlin Heidelberg 2017

\section{Erratum to: Exp Brain Res \\ DOI 10.1007/s00221-016-4856-5}

The original version was inadvertently published by the Publisher without the revised and corrected figure part, Fig. 2c. To see the article in its entirety, including the correct Fig. 2c, please go to http://link.springer.com/ article/10.1007/s00221-016-4856-5.

The revised figure part, Fig. $2 \mathrm{c}$ is given below:

The original article was corrected.

The online version of the original article can be found under doi:10.1007/s00221-016-4856-5.

Stefan Panzer

s.panzer@mx.uni-saarland.de

1 Institute of Sport Science, Saarland University, Campus B8.2, 66041 Saarbrücken, Germany

2 Institute of Sports Medicine, University of Paderborn, Paderborn, Germany

3 Developmental Psychology Unit, Department of Psychology, Saarland University, Saarbrücken, Germany 

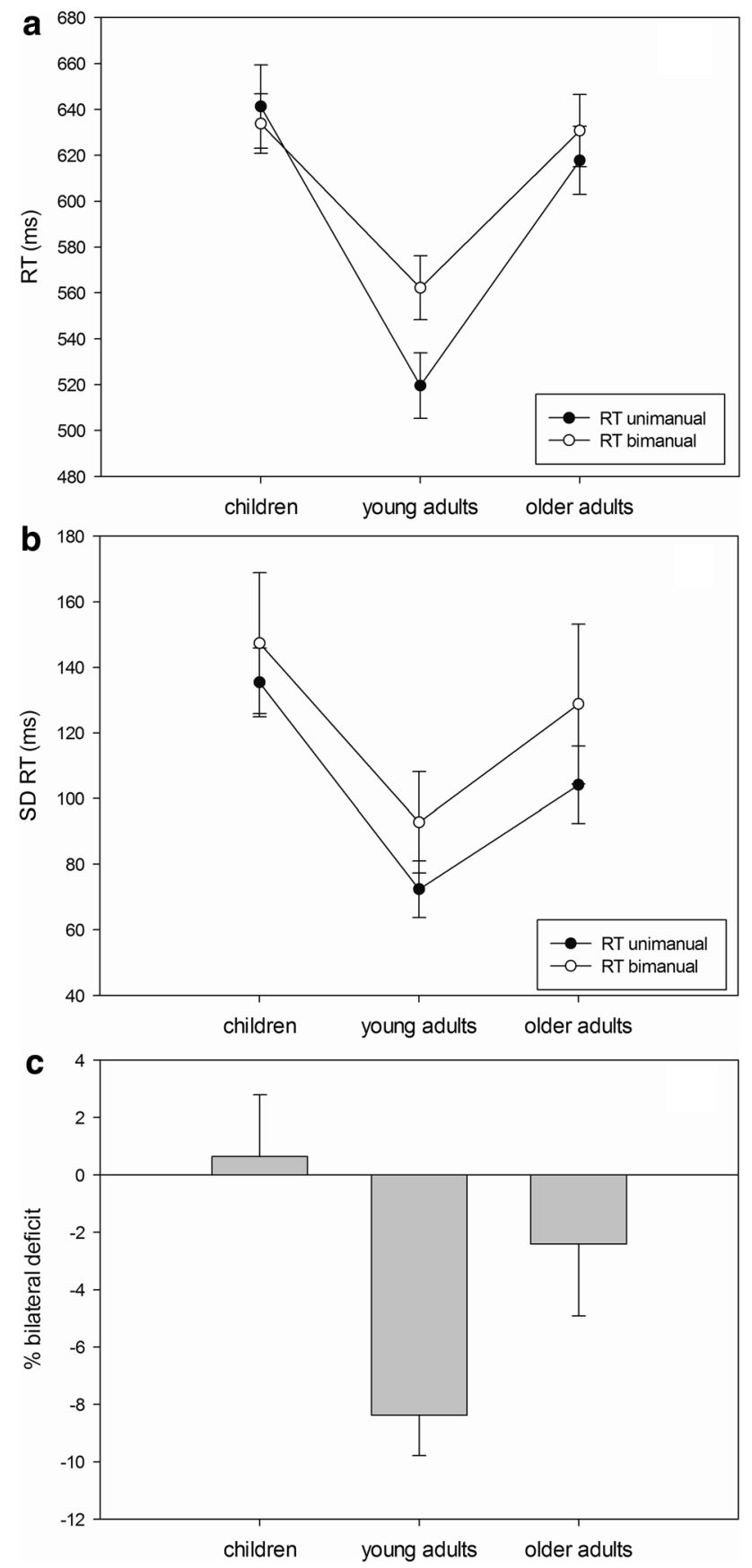